\title{
When is freezing harmful?
}

Authors' reply Pulmonary vein stenosis is a rather rare complication of cryobaloon ablation $(0.17 \%$ according to Andrade et al), ${ }^{1}$ but it is observed much more frequently after radiofrequency catheter ablation and ranges from $3 \%$ to even $42 \%$, depending on the method of venous stenosis assessment and the ablation technique used. ${ }^{2} \mathrm{~A}$ growing number of performed procedures, regardless of their type, translates into a higher number of observed complications. The aim of our article was to attract the attention of pulmonologists to pulmonary vein stenosis as a potential cause of hemoptysis and lung infiltrations and prompt radiologists to search for even a mild degree of pulmonary vein stenosis in chest computed tomography in symptomatic patients. It will shorten the time to diagnosis and markedly reduce costs, allowing to avoid invasive procedures such as video-assisted thoracoscopy.

We would like to thank you for your interest in our article.

Author names and affiliations Łukasz Kasper, Iwona Gross-Sondej, Beata Machalica, Jerzy Soja, Wiesław Pawlik, Krzysztof Sładek (ŁK, IG-S, JS, KS: Department of Pulmonology, Jagiellonian University Medical College, Kraków, Poland; BM, WP: Department of Radiology, University Hospital, Kraków, Poland)

Corresponding author Łukasz Kasper, MD, PhD, Klinika Pulmonologii, Uniwersytet Jagielloński, Collegium Medicum, ul. Skawińska 8, 31-066 Kraków, Poland, phone: +48 1243052 66, e-mail: kasper@mp.pl

Conflict of interest The authors declare no conflict of interest.

How to cite Kasper $€$, Gross-Sondej I, Machalica $\mathrm{B}$, et al. When freezing is harmful? Authors' reply. Pol Arch Med Wewn. 2016; 126 (4): 297. doi: 10.20452/pamw.3394.

\section{REFERENCES}

1 Andrade JG, Khairy P, Guerra PG, et al. Efficacy and safety of cryoballoon ablation for atrial fibrillation: a systematic review of published studies. Heart Rhythm. 2011; 8: 1444-1451.

2 Staad EB, Rossillo A, Saad CP, et al. Pulmonary vein stenosis after catheter ablation of atrial fibrillation: emergency of a new clinical syndrome. Ann Internal Med. 2003; 138: 634-639. 